\title{
What Comes from Confronting a Growing 'Certainty'? Exploring How UK Journalism Reports the Politics of Climate Change
}

\author{
Julian Matthews \\ Department of Media and Communication, University of Leicester, UK
}

Copyright $(2016$ by authors, all rights reserved. Authors agree that this article remains permanently open access under the terms of the Creative Commons Attribution License 4.0 International License.

\begin{abstract}
This paper discusses a growing 'certainty' on the seriousness of the climate change issue observed in UK elite reporting. It identifies this type of reporting as produced by a process to 'domesticate' the issue in the UK. Important within this domestication process is an elite politicization of climate change where political actors demonstrate forms of token 'cultural leadership' alongside voiced concerns to combat this potentially disruptive issue. Equally significant are UK journalists' efforts to mediate these frequent elite commentaries according to the interests and the practices of elite journalism logic and, in turn, to report them alongside scientific and civil society voices and perspectives on the issue. This paper introduces the frames and voices found in the UK elite reporting and recognises how this coverage contrasts with coverage argued previously to be replete with climate scepticism and/ or elite challenges to climate change. Further, with UK domestication set to intensity, it suggests that we will likely see elite UK journalism confronting a growing controversy over the policy and the actions used to adapt to and mitigate the outcomes of climate change. Not only will political elites seek to hone their claims making to respond to the concerns raised by international political actors then but also to quell growing criticism voiced by interest groups on the home front. Given this developing situation, we may even see elite journalistic voices joining reporting and acting their fourth estate role when calling for further action.
\end{abstract}

Keywords Journalism, Climate Change, Framing, News Voices, Legitimation, Journalistic Logics, Politicization, Domestication

\section{Introduction}

What happens when elite journalism confronts a growing staged political certainty around the importance of the climate change issue that is performed by elites? Studies of media reporting appear to follow some way behind research found elsewhere in the academy that recognises the prevalence of changing and consolidating 'imaginaries' of climate change in society (Levy and Spicer 2013). Currently many studies of media content continue to assume that news reporting is universality reinforcing an uncertainty surrounding the issue and hosting a challenge to its legitimacy. By adopting a broader focus on the issue, it is possible to ascertain a sense of its developing mediation. For example, analysing its framing over time reveals a level of complexity that underpins the reporting of climate change. Similarly, comparative analyses of its coverage show that representations of the issue differ between the media in different countries - a process we can label as 'domestication' (see Gurevitch et al. 1991). Neither described tales of doom-laden future scenarios (Anderson 2009) nor the often-cited evidence of scepticism (Antilla 2005), capture this reporting generally or accurately depict the specifics of UK coverage as Boykoff and Rayan (2007) have previously observed, for instance. The important differences within the UK reporting in particular hint at mechanisms reinforcing a domestication of the climate change issue in the UK and, likewise those that are affording a staged legitimacy and credibility to it in its corresponding news coverage. Recording the levels of these characteristics would allow for, it follows, a forward facing analysis of its development in any future coverage.

To understand the present and future reporting of climate change, this paper introduces the 'domesticated context' that informs the UK reporting as important to such an analysis, including a move made behind the headlines to observe a political context (politicization) and a journalistic context (mediation) shaping this reporting. It argues that reactions to the issue form within the process of politicization and these reactions include commentary on the legitimacy of climate change as a serious problem. Reactions are made concrete and then reproduced in the form of political frames. 
These discursive frameworks offer the material that journalists will use and adapt within their writing of news stories. Nonetheless, an understanding of the functioning of news journalism in the process allows us to recognise that these discursive frameworks (frames) are always mediated according to 'journalistic logics' (Matthews 2015) and these inform the news story production process. Incidentally, these logics appear and operate differently across the news ecology. For that reason, it is important to acknowledge the influence of these combined processes to be able to understand the configuration of the UK coverage over time and that which will expand into the future. Before this paper discusses the UK elite news coverage, it will say more about the relationship between the processes of politicization and mediation and the research study on which this discussion is based.

\section{A Wider View: Climate Change and Politicization}

As has been argued above, the material that characterizes the reporting of climate change has its origins in the wider process of the 'domestication' of the climate change issue or put simply a discussion of it from a position of national elite concerns. To understand the domestication of climate change then, it is important to examine how climate change is being politicized and the likely motivations that shape the national politicization process. In the case of a seriously disruptive issue (such as climate change), there are motivating forces that inform the production of political commentary. From what we have heard about the UK media, it appears to offer a useful case that features unusual political reaction to this 'significant' issue. Habermas' (1998/1976) predictions on a coming of a legitimation crisis, states that some issues (like this) represent 'crisis tendencies' in advanced capitalist societies on the basis that these highlight 'negative outcomes' produced by capitalism that the state can no longer control or adequately hide from, mediate to, their populations. Symbolising then an issue with unpredictable development, climate change is understood as a pertinent example (alongside other issues) that is destined to become politicised in this way. Habermas (1971; 1998/ 1976) expresses that 'politicization' grows intense in the interactions between the state, political actors and other interested groups as these issues develop in importance. Through societal dialogues, that are sometimes visible in the mass media and elsewhere, the state and political actors toil in their position to sustain a form of cultural leadership (often in representing their action in the face of climate change) while facing interest groups who challenge these words and deeds as part of their alternative accounts and voiced criticism. The view that climate change or other issues share 'crisis tendency' status and within them contain the seeds to grow a substantial crisis in political legitimacy however has been challenged (e.g. Held 2006). Nonetheless, practices to make visible the 'ills' associated with environmental despoliation and to evaluate the actions of the government and other actors in response to them are repeatedly emphasised as common features of the 'late modern', 'risk' or 'network'- society (Beck, 1992; Castells 1997; Eder 1996). This wider literature introduces various forums involved in this politicization process. Still, most sociological writing (with the exception of some - e.g. Hannigan 2006) has paid less attention to the mass media as an important site for this contest. Similarly, it is unfortunate that media research rarely widens its research horizons to engage directly with the organized politicization process evolving outside of the media. What this latter literature does provide, nevertheless, is an analysis of the visibility given to this issue. In addition to offering a measure of its perceived serious and the state of argumentation, this analysis provides insights into the outcomes of the efforts of actors to sustain and challenge political legitimacy to which we will now turn our attention.

\section{News Journalism and Climate Change}

Putting criticisms of the scope of research to one side, we must recognise that media and politics research has discussed clear connections between the wider politicization of issues and their reporting. Political communication scholars in particular now accept that news coverage will incorporate or 'index' the outcomes of the politicization of an issue as was first suggested by Bennett (1990). As part of a process to focus their news writing, journalists will use insights from political commentaries and elite claims making (Entman 2004). Further assisting in this process is the common form of their news reporting. As underpinned predominately by 'news events' the process of story writing responds favourably to elite discussion that will signal the importance of an issue for the journalist. Also, it is the desire of journalists for authoritative guidance on issues that likewise informs their news reporting. Often elite commentary functions to configure the thoughts of journalists on an issues' legitimacy and thus enable their writing to situate an issue within established classifications based around ideas of 'consensus', 'legitimate controversy' or 'deviance' (Hallin 1986). Retrieving the configuration of the issue from elite commentary then assists journalists in the selection of a newsworthy aspect of an issue to report (contentious or not, for example) and their decisions to take over the voices that will be included and allowed to speak about it. Research studies that examine the reporting of climate change have introduced, often independently of each other, various themes in its news coverage that reflect the complexity of perspectives that have formed within a developing politicization of this issue.

As has been suggested, combining the findings of these studies shows a distinct patterning within news coverage. Revealed in these overviews is how various frames on climate change emerge, alter and evolve over time. Studies 
describe coverage in the period of the emerging reporting of 'global warming' in the 1980s for instance as reproducing science and political frames predominantly. Appearing across the coverage, these frames work to 'explain' and 'predict' the issue, to offer 'judgements', and to suggest 'remedies 'respectively (Trumbo 1996). The configuration of this early reporting allows the observed political framing to dominate in overall number and to shape the direction of early news discussions. As has been inferred above, later analysis of coverage shows a violent disruption to the set pattern of these early frames. Studies identify noteworthy changes including evidence of an acute transformation in the previously straightforward and largely unproblematic representation of climate science (Weingert et al 1990). Science frames reproduced in 2000s for instance include criticisms of climate science and instances of a general scepticism directed toward the legitimacy of the climate change issue. As interested to explore these developments, Antilla (2005) reports on a significant growth in scepticism frames appearing in the early 2000s and provides insights that confer with other studies that also suggest media coverage includes scepticism as part of its mediated debates on the issue (Boykoff and Roberts 2007).

A transformation in the politically focused frames in coverage is recorded as another significant change in the reporting of the climate change issue. An evolving political reporting has introduced prominent international high profile climate summits and political talks and has represented these with the previously recognised 'conflict' or 'negotiation' frames (Lockwood 2010). The evolving reporting in addition to reflecting the dynamism that characterises science and political framing also diversifies its discussion of the issue. An increased amount of industry and economic framing has emerged across the coverage for example and emphasised there the possible economic solutions to climate change (Zehar 2010) in addition to a general 'industry perspective' on the issue. These industry frames differ markedly from the 'technological fix' frames observed in previous coverage (e.g. Wilkins and Patternson 1991) and offer supporting evidence of a diverse and staged news presentation of the climate change issue. Whether the recorded changes signify a complexity at the heart of framing and collectively reflect a 'spectacle' performance of concerns over the issue (Cottle 2009) by elites can be examined and reflected on later. For now, it is important to consider the implications of this politicization for the openness of reporting to the voices of different institutions, groups and individuals, including those of interest groups.

Unfortunately, previous research has not explored the influence of this politicization and political framing on the dialogical character of its coverage, directly. Their findings reveal nonetheless that the status and the motivations of the included media actors shape their presence and their performance in this coverage. Habermas (1989/1976) and others' thoughts on politicization usefully predict for example that political elites will feature prominently here (Gaber 2000) and use their presence to shape the political contours of these news discussions of the issue (Trumbo 1996). Scientists share the news stage with politicians in the same way they share the news agenda. However, they enter reporting with the intention to maintain control over how news stories discuss their research findings and their general expertise (Tosse 2013). Industry representatives materialize on the news stage in a lesser amount than the above speakers do and appear there with contrasting intentions. Performing mostly an 'industry perspective' (Holmes 2010) on the issue in this space, they on occasion and in disguise of front organisations openly questioned established climate science that threatens their interests, it is suggested (Monbiot 2007). In sum, studies of news voices infer that the authority and perspectives of politics, business and science mark the discursive space in which other voices must negotiate. Among these other voices, interest groups in particular are recognised to be gaining increased success over the level of that achieved previously. The persistence of the issue on the agenda has allowed them more opportunities to take a place on the news stage and comment (Doyle 2007).

\section{Mediating the Climate}

Moreover, it is the activities of journalists and news organisations (i.e the process of mediation) that have also shaped the reporting of the climate change issue. Studies show that journalists follow general routines and processes in their reporting activities and that these structures assist in a routine process to identify and shape a recognisable 'newsworthy' climate change story (for a review see Anderson 2009). The explanatory potential of any generalised view of news production processes can be questioned however, when we consider the different types of news writing that are produced across an ecology of news outlets. As there is clear evidence that what is considered newsworthy differs among sections of news outlets, the use of the term of 'journalistic logics' can help to grasp the differentiated practices they follow. For one thing, it reminds us that journalists work with different sets of organising principles or 'logics' when news making. Although this insight connects well with Altheide and Snow's (1991) view of the commercially focused 'news format' functioning in news making, the diversity in which we speak is addressed better with the idea of differentiated journalistic logics. In practice then these logics operate in newsrooms to inflect coverage to the intentions and ambitions of the elite, the mid market and the lower market news forms. As embedded in the fabric of journalists' news work, an 'elite journalistic logic' that we will examine later for example, shapes the reporting of in-depth political and economic coverage and in the process provides space for those voices it considers as relevant to these matters. The stories it manufactures differ then to the coverage produced by other significant logics (i.e. mid market logic or lower market logics). Even so, as similar to them, elite journalistic logic reflects the rules that govern the reproduction of political frames, other content and voices 
to include. Given then what we now know about this reporting, the rest of the paper will explore the specifics of a UK news coverage that is shaped according to elite journalistic logic and to political framing. It will also reflect on how this reporting will likely develop in the future. First, however, the paper will introduce the process devised to explore the character of the UK news coverage.

\section{Method}

The following discussion reports on research that examines connections between the politicization and the mediation of the climate change issue in the UK press (i.e. its domestication). The study selected four UK elite newspapers (The Times, The Telegraph, The Independent and The Guardian) and collected a ten-year sample of their coverage $\left(1^{\text {st }}\right.$ Jan $2000-31^{\text {st }}$ Dec 2010$)$ to explore potential changes in the elite reporting of the issue. In searching for individual articles, it employed the basic search terms 'global warming' and/ or 'climate change' in the nexis database. After cleaning for duplicate or non-relevant stories, the researcher adopted every $10^{\text {th }}$ article consecutively across their coverage to produce a random sample of 1379 stories. These stories were then taken forward for analysis.

This analysis was conducted in two phases. The first phase examined the characteristics of coverage to grasp the legitimacy given to the issue, including: (i) frames, (ii) story themes and (iii) the causes behind their writing. As part of this process, a systematic technique was used to identify the presence of a dominant frame in each story. The procedures of linguistic analysis (see Baker and McEnery 2005) inspired this process and in practice these helped to record the relationships between proximate wording and, in turn, to develop these observed relationships into frames that represented the coverage ${ }^{i}$. Specifically, this process located the wording 'climate change' or equivalent in the headline and/ or beginning of the news story before tracing the syntactic patterns between it and other proximate words (or concordance). Through a simple process of pairing together similar observations, these patterns were placed into categories. When the analysis was complete, eight frame categories remained, including those of: (i) climate change as an issue to combat; (ii) threat /risks of climate change; (iii) effects / predictions of climate change; (iv) climate change as a scientific process; (v) scepticism of climate change; (vi) talk /debate about climate change; (vii) action on climate change and (viii) inaction on climate change. The individual headlines observed in the process were then compared with the rest of their stories to produce categories on the (i) story themes and (ii) the expressed cause behind their writing and both were analysed as part of a general content analysis.

The second phase examined those news voices that were reproduced in the elite reporting. Within this phase, a content analysis was used to explore the ordering and the placement of voices in news stories. The analysis recorded the professional / institutional backgrounds of individual news actors and recoded the list of individual voices into eight groups, including those of: domestic politician, international politician, industry, scientists, public institutions, interests groups and associations and individuals. Following this process, the study measured the position of each voice within the news story and the form of their news entry. Finally, the analysis compared the findings from the mediation of the content and the mediation of the voices to explore the relationships between them. This produced a set of interesting and predictive insights that will be discussed now.

\section{Findings}

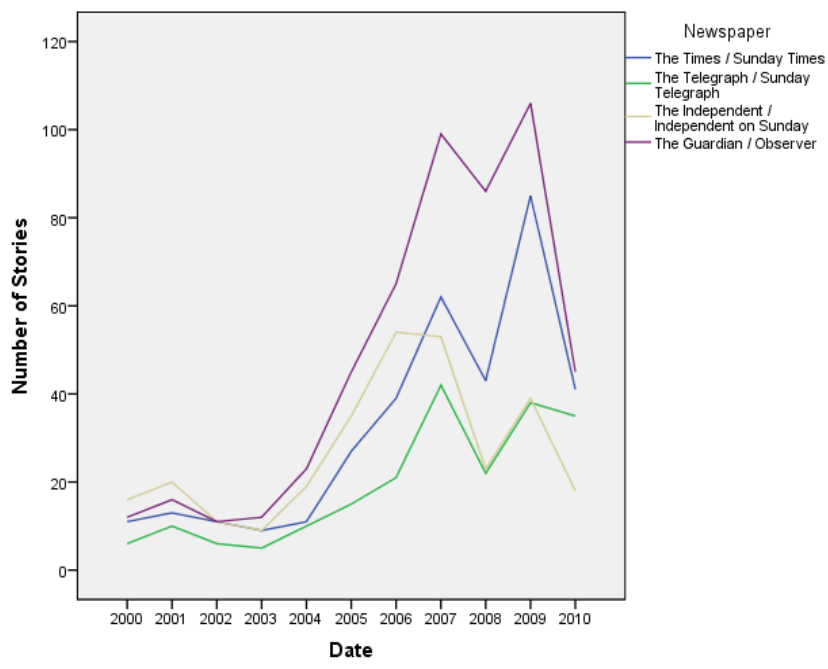

Figure 1. Number of Stories by Newspaper by Date

As has been explained above, this paper is interested in the relationship between constructed ideas of climate change and actors perspectives on the issue and how these are reproduced in the selected elite news coverage. After examining the selected newspapers' reporting, we find that these cover the issue in marked ways ${ }^{\text {i1 }}$ (see Figure.1). The Guardian's reporting for example produces a higher proportion of coverage overall in comparison to the other newspapers, significantly more coverage than the Telegraph over the ten-year period for instance. Analyses of issues of this type are likely to observe different reporting rates, it has been suggested. As such, studies argue that the differences found in the routine selection of this particular news topic will likely reflect the influence of the newspapers' ideological / political stances on their news selection practices (see Carvalho and Burgess 2005). With those differences acknowledged however, one cannot disguise the observable similarities in the levels of newspaper reporting. The growth in this coverage over time and the included peaks and troughs reveal an influence of the external environment on these newspapers' reporting. Research that recognises similarities in climate change coverage (e.g. Shehata and Hopmann 2012) often argues that common 
levels of media attention, such as is observed here, follow from the presence of significant newsworthy events (e.g. climate change conferences or moments of controversy, for example). This will be undoubtedly true of these newspapers reporting, but such a view of their news selection process needs to be revised in the face of the level of observed continuity in reporting over time. These types of significant newsworthy events then must be seen as only part of the influence on their reporting. In other words, it is the efforts of elites and others in the UK to frame and speak about climate change (or to engage in the process of politicization) that is shaping this particular coverage (see Figure.1).

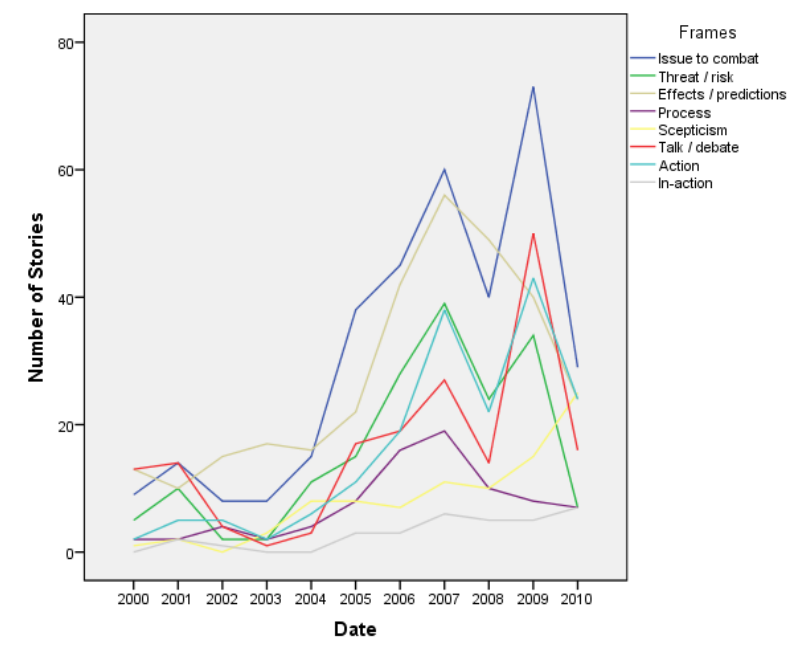

Figure 2. Number of Stories by Frame

Working with an aim to observe the influence of issue politicization on this news coverage, demands then that we analyse its specifics, beginning with the similarities found in its content (i.e the reproduced frames). A completed analysis of this coverage reveals that these newspapers reproduce eight recognizable frames on the climate change issue (see Figure.2) and that they replicate these frames in relatively equal number over the period including over the peaks and troughs of 2007 and 2009. In addition to providing evidence of the general influence of issue politicization on this reporting, the observed frames offer insight into the linguistic constructions of the issue that have been reproduced as part of the process. An analysis of the frames provides then evidence of the continuities and the complexities in the construction of this issue in the reporting (see appendix for an outline of frame content). Here, climate change is introduced in the coverage as (i) a 'real process' contrary to the scepticism of climate science observed elsewhere and this is explained to have present and tangible (ii) 'effects' and (iii) potential future 'risks / threats' The issue, as defined by these outcomes, is introduced as requiring (iv) 'combating' and (vi) discussion and to be the subject of (vii) 'action' and (viii) 'inaction'. A brief reading of frame content provides therefore a general insight into the shaping of the issue. That the meanings in coverage introduce climate change as a legitimate and serious issue is an important finding and one that questions the assumed relevance of the presence of widespread scepticism in the domestication of issue in the UK as is seemingly found elsewhere. It is a less surprising insight though when this is situated alongside Habermas ideas about the public relations efforts of elites working to 'be seen to act' in the face of the serious issue. Nevertheless, this outline offers an incomplete picture. As we have heard above, the news journalists of these newspapers employ elite journalistic logic to mediate issue politicization into news story content. What follows will explore more of news coverage produced according to the wider politicization of climate change (frames) and the elite journalistic logic (see results in Table.1). The analysis will group frames around their common foci of political, science and civil society perspectives, rather than discuss them individually and will begin by discussing reporting that demonstrates the relationship between politics and climate change.

Table 1. Comparison of Actors by Frame

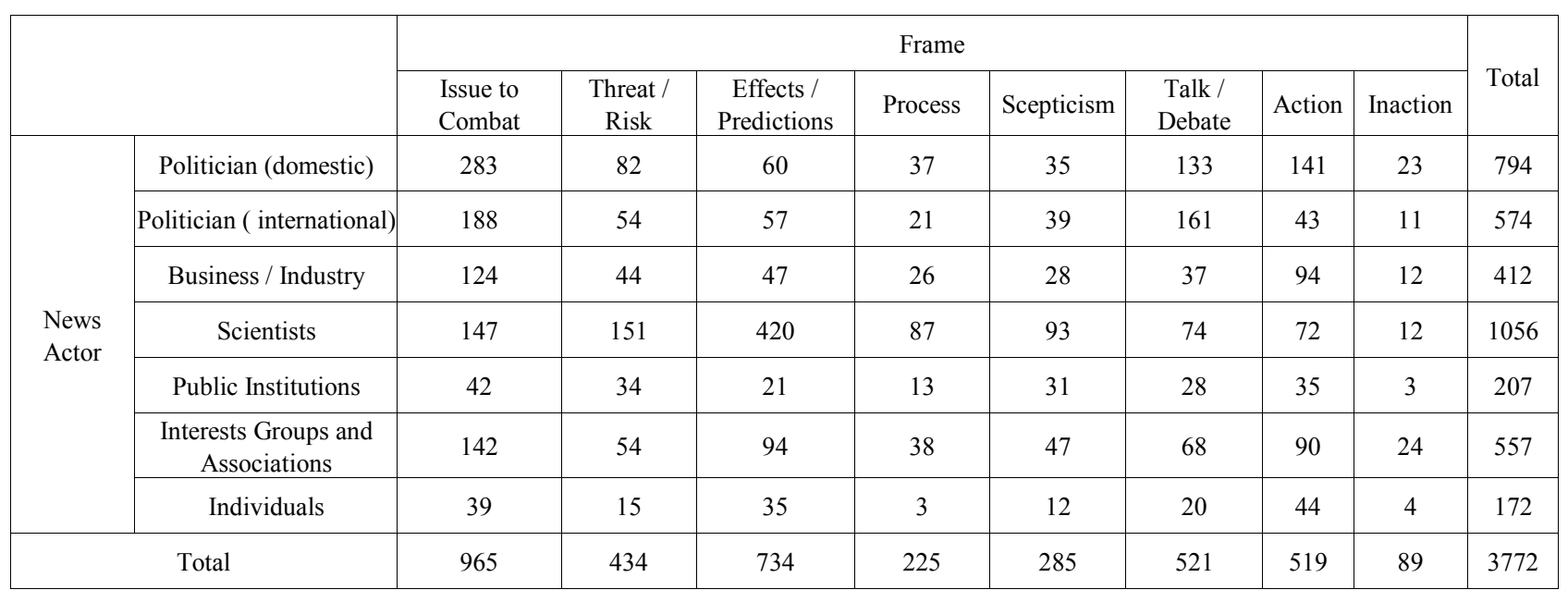




\section{Politics in Action}

Situated against the backdrop of the politicization of climate change, we find frames that describe 'politics in action' or, in other words, the outcomes of an ongoing construction of a discussion of climate change by political elites in the UK. These reported frames introduce political positions on climate change and the reactions of others to them. One of the most prolific positions introduces climate change as an issue requiring elite attention or 'combating' (issue to combat frame - 339 stories). The presence of a voiced desire to 'fight', 'tackle' or 'deal with'...climate change is an outcome reproduced often from the UK politicization process and one that reveals the unique character of the domestication of this issue in the UK. Looking inside the news coverage, we see that this frame supports a range of stories focusing on national politics, the UK economy and discussions of the UK government's relations to other international governments. Exploring the role that voices play in this reporting provides a deeper understanding of how a position on the 'combating' of climate change is being discussed. Interestingly, connections appear between the reproduction of the framed content and the views of political actors and this link supports the view that elite claims making is being reproduced across the reporting. In effect, the reproduced reports and /or voiced statements from politicians and business representatives initiate these stories and shape a configuration of voices that appear within them. Further sustaining the view of climate change as a legitimate issue across the coverage is a reproduction of another frame in this category - "climate change issue as a scientific process'. When reproduced in coverage $(n=82)$, the frame introduces legitimate climate science as a basis on which to explore discussions from political and business perspectives. Developing from these initial discussions of climate science within the coverage then are non-contentious business reactions to climate change, domestic political discussions about government policy and responses from science and other perspectives to future change.

In addition to discussing a political perspective on climate change, the sampled UK coverage comments on the political action in response to the issue (action frame - 177 stories). This constructed view of political 'action' stresses 'action' undertaken in response to the seriousness of the issue. Offered in these news scenarios then are opportunities to represent the 'actions' of both elites and non-elites and further, we notice, their combined presence symbolises an openness that an elite journalist logic configures in this coverage. The framed stories describe action in response to the climate change issue as is found in (i) the planning and introduction of political policies, (ii) the economic solutions to the issue and (iii) those instances of protest action for the most part. Again, there is a connection to observe between the recorded frames and the voices and this link underscores our insights into the influence of politicization on the process of news making. Introduced in these news discussions are the voices of politicians (domestic and international) and interest groups for example and both appear in positions of authority to speak about climate change policy from different perspectives (see Table.1). Another compatible frame in this coverage widens the theme of action to include verbal action (talk / debate frame - 178 stories). Action is introduced here as present within three spheres of formalised elite discussion, including those of (i) climate change conferences and summits, (ii) domestic political discussions and (iii) those forms of discussion held between business and industry representatives. International political conferences are the first of these (such as those reported in 2007 and 2009) that shape the presentation and the parameters of a significant number of stories. Nonetheless, combined, this coverage explains the machinations behind, and outcomes from, these elite formalised discussions on the issue and further it uses particular news formats so as to reproduce conflict between their verbalized positions. It offers a base on which to perform reaction to wider discussion then and that which includes the voices found outside of the formalised world of politics (e.g. from science and business). Coverage framed in this way uses these voices to explain the implications of the talks and the voices of interest groups in particular as 'critical' experts.

Finally, significant to the elite reporting of political reaction to climate change is coverage that discusses 'scepticism' (scepticism frame - 90 stories). The presence of this frame appears noteworthy when it is considered in the context of the previous studies on the reporting of this issue. Significant therefore are how these stories serve to challenge expectations of reporting that addresses scepticism (i.e. a questioning of climate science and the prevalence of climate change sceptics - see Antilla 2005). Here, the framed stories introduce reactions to scepticism / controversy rather than providing a discursive platform for critics of climate science. Further, the voices in these stories reflect the focus identified in this frame. Present within them is a configuration of voices that speak about their reactions to instances of scepticism and / or controversy. As part of the reporting, the comments of scientists dominate in overall number and these challenge the questioning, if not sceptical, positions that appear in stories (i.e. scepticism originating from international (particularly US) politicians). Elsewhere, stories provide other actors, including politicians, industry and interest groups, with an authority to challenge instances of controversy or general scepticism. In addition to the political focus of these frames on climate change, the UK reporting introduces also other frames that focus on science and civil society perspectives.

\section{Scientific and Civil Society Insights}

The discussion of scientific perspectives of climate change in the news media is well established (see the review, above). In this sampled coverage, science frames appear however closely related to the less well acknowledged civil 
society frames. Bonding these frames together are a set of news discussions on the effects and the predictions of climate change (effects / prediction frame -304 stories) in the first instance. In addition to the common ground these frames offer to both science and civil society perspectives, these also provide a clear dividing line between them. Found in this group are therefore (i) framed stories that follow a scientific focus to explain selected impacts and consequences of climate change and (ii) those framed stories that draw on different foci (civil society perspectives) to explain the effects and predictions related to the domestic UK economy and politics. A feature common to both presentations and one that contrasts with political frames is their lack of contest over their subject matter. The UK coverage reflects a consensus on the climate change process and its effects. Of course, this outcome is reflected in the relationship between story content and the accompanying news commentaries. Nearly two thirds of these stories allow a science voice to speak with authority and to define the contours of the accompanying news discussion (199 stories out of 304). Reporting shaped in this way simply reinforces the importance, and thus the authority, of the orthodox scientific explanations of the climate change issue. It also provides a stark challenge to the assumed presence of a questioning of climate science in news reporting of climate change that was discussed previously.

A similar feature in this framed coverage is an observed configuration of framed stories that in their place introduce 'risks' and 'threats' associated with climate change as straightforward and uncontested scientific calculations (threat / risk frame - 177 stories). As was found in coverage beforehand, there are other framed stories that accompany the scientific discussion of risk. These include claims made about the general effects or the consequences of climate change and provide space elsewhere for discussions of 'risk and threat' in the context of particular domestic political and business related discussions. A unique feature of these stories is the diversity of voices they house and how their presence supports a consensus on the issue rather than a contest over the issue that is either commonly found in other frames or is one assumed to be present by previous research. In effect, these voices, particularly those of scientists and domestic politicians, serve to contextualise the notion of 'threat' (see Table.1). Framed stories describing 'threats / risk' also provoke wider commentary on the issue and therein offer space for the non-elite (civil society) interpretations at such times. Included in these spaces are both the voices of individuals and interests groups and their presence supports previous observed insights into the growing diversity of the perspectives within the sampled coverage.

In addition, a general civil society perspective is observed as present within the reproduced coverage and as providing insights into actors' inaction in response to the climate change issue. Stories on inaction (inaction frame - 32 stories) direct attention toward those activities of actors functioning within domestic politics and industry and international politics mostly. Taken at face value, the presence of these framed stories would most likely signify the actions of one set of actors as criticizing another group - an outcome that is predicted by Habermas and others. The locations of criticisms are more complex than is suggested here however, and originate from both elites and non-elites. Sometimes therefore it is the claims making of elites that provides the catalyst for stories that in turn secure a vantage point for their commentaries. At other times, other voices shape alternative news discussions. As we have recognised previously, interest groups do emerge to offer most of the criticism focused on the actions of domestic politicians. In these instances, they lead news discussions on the inability of elites to deal adequately with climate change and from their privileged positions speak the most elaborate range of commentary on inaction ahead of other voices in the coverage such as those of politicians, scientists and industry representatives. Overall, this configuration confirms the focus of their growing communicative power and their presence in this type of news coverage on climate change.

To sum up, these insights into the observed frame categories provide an overview of the communicative efforts of political, industry and scientific elites and non-elite actors who participate in the politicization of climate change in the UK. The outcomes of their reproduced communicative efforts have produced coverage focused on climate science (in the absence of climate scepticism), international political discussion of the issue alongside domestic political discussion and various business and civil society focused commentaries. This overview of the UK reporting challenges then our previous sense of coverage of this issue and encourages us to acknowledge, and reflect on, the observed differences in this domesticated reporting. In addition to the points raised above, the analysis has also demonstrated that journalists working with journalistic logics shape the representation of the communicative activities of these nationally bound elites. In this case, elite journalistic logic has intensified the range of discussion and criticism and widened the involvement of others in the reported discussions of the climate change issue. The criticisms and those challenges made to the self-presentation and general inaction of political elites is an important feature of this elite coverage for example. Still, what does this tell us about the future of the UK reporting of climate change?

\section{The Ongoing Domestication of Climate Change}

Given what we have heard, it is entirely sensible to argue that the developments in the reporting observed above will likely intensify in the near future. Up until this point, the process of the domestication of the climate change issue in the elite UK media has been based on a political recognition of the processes of climate change and their potential effects and consequences. For the critic, this reporting provides 
evidence of the discursive actions to maintain cultural leadership by elites through acknowledging this issue and demonstrating where possible instances of action taken in response to it. Framed in this way, the news creates spaces for the discussion of climate science, the discussion of solutions even, if only limited or commercially focused ones, and of course spaces for criticisms of elite words and deeds by interest groups. We can suggest that in the future these features will likely persist and in the process will transform future news reporting. The growing backdrop of 'certainty' over the issue will act in this way and provide a motor for the politicization process. It will, in turn, transform the nature of the reporting of the issue. In real terms, this means that there will be less attention given to future predictions as upcoming reporting will be focused on the management and the prevention of climate change. In addition to a transformation in the discussion of the issues, another change will appear in the form of a greater coherence in the societal response to climate change. Alterations of this kind will intensify the scrutiny others apply to those comments and actions offered by political elites. Criticisms of elite action will probably focus on their consistency in managing and acting on the issue. At this stage in development, critics of elite inaction including interest groups will be predisposed to expose any instance of the 'token' politics to which Habermas infers is central to current elite political actors' actions. This process may lay the potential foundations for a crisis in elite political legitimacy that was introduced at the beginning of the paper.

Nevertheless, the operation of journalistic logics will be essential to guiding the journalistic mediation of the developing politicization process into news coverage in the future. On the basis of what we have observed of the operation of elite journalistic logic so far, its future mediating of the issue will be underpinned by growing political certainty. This will probably provide a widened platform for the representation and scrutiny of any action or inaction taken in the face of the developing issue ( hence this type of framing is likely to increase). Certainly, the elite press will offer a conduit for the representation of challenges to political legitimacy on climate change from established critics. Another outcome of elite reporting in an era of performed political consensus on the issue might be observed instances of position taking on the part of the media. It is entirely plausible to suggest that elite newspapers will be observed to be exercising their fourth estate role and working in this way to hold political elites accountable for what they say and do or do not do in the future - and thus will become an active voice in the discussion and not only a 'passive' conduit for the thoughts of others.

Whether elite press champions the issue or not, their type of coverage will be less prevalent among the reporting of other news outlets found in the UK media ecology, however. Thus far, the mid market and lower market journalistic logics already shape products with news agendas and representations that differ from those of the elite press. It is reasonable to assume therefore that the limited attention climate change receives from these sectors will likely continue. There is a caveat to this conclusion, however. The developing politicization process outlined above may well in fact inform increased coverage of the issue shaped by these logics (i.e. continued domestication). Attracting their attention in this case will be the newsworthiness to be observed in the growing criticism that comes from conflict between political elites, interest groups and the elite media over the issue. Voiced irreverence to government handling of significant issues recognised as part of the lower market tabloid forms (Matthews and Brown 2012) for instance may in this case form the basis of these newspapers' introduction into a wider discussion of the issue in the future.

\section{Conclusions}

This paper has reflected on the scenarios that journalism is likely to encounter in the process of reporting the ongoing politics of climate change. Analysing the contours of elite UK newspaper reporting has revealed several trends toward the presentation of the climate change issue as a 'legitimate' issue and one that requires forms of political action. Using the findings from this analysis, the paper has explored the future politicization and extended its analysis to comment on a variety of features that will be expected to occur within UK reporting. Whether or not the outcome of the future politicization and mediation of this issue will lead to the political crisis that Habermas imagines or a form of 'slow burn crisis' explained elsewhere (Nohrstedt 2010), it is probable that journalism will be called upon to stand between and mediate those conflicting groups or even take a position in these news discussions. Whatever the outcome, journalism and its practitioners will be placed as increasingly central to the discussions of this issue and in turn these will face the challenges common to their imagined fourth estate role as they seek to report on a growing certainty over the climate change issue. 


\section{Appendix}

\begin{tabular}{|c|c|}
\hline Frame & Description \\
\hline Issue to combat & $\begin{array}{c}\text { Framed coverage describes desire to combat ('fight', 'tackle' and 'deal with'...) the issue in context of national } \\
\text { politics and the economy and the UK government's perspective in relation to those of international governments. }\end{array}$ \\
\hline Effects / predictions & $\begin{array}{c}\text { Framed coverage introduces scientific research findings and explains selected impacts and consequences of } \\
\text { climate change. It also draws on other foci to explain effects and predictions in context of the UK domestic } \\
\text { economy and politics. }\end{array}$ \\
\hline Talk / Debate & $\begin{array}{c}\text { Framed coverage introduces discussions of the effects and policy implications of climate change and other } \\
\text { matters within the following sites: (i) international climate change conferences and summits, (ii) domestic } \\
\text { political discussions and (iii) discussions among business and industry representatives }\end{array}$ \\
\hline Action & $\begin{array}{c}\text { Framed coverage introduces action in response to the climate change issue, including discussions of the } \\
\text { planning and introduction of political policies, solutions posed by business representatives and protest action } \\
\text { offered by non-elite actors. }\end{array}$ \\
\hline Threat / Risk & $\begin{array}{c}\text { Framed coverage introduces the threats / risks of climate change as straightforward and uncontested scientific } \\
\text { calculations or poses these general consequences in the context of particular domestic political and business } \\
\text { related discussion. }\end{array}$ \\
\hline Scepticism & $\begin{array}{c}\text { Framed coverage introduces reaction to small number of incidents (including 'manipulation of data', 'mistakes' } \\
\text { and 'blunders' in climate science) and reaction to evidence of scepticism / controversy generally. It does not } \\
\text { provide a discursive platform for criticisms of climate science. }\end{array}$ \\
\hline Process & $\begin{array}{c}\text { Framed coverage discusses climate science as precursor of non-contentious business discussions of climate } \\
\text { change, domestic political discussions about government policy and responses from science and others to future } \\
\text { change. }\end{array}$ \\
\hline Inaction & $\begin{array}{c}\text { Framed coverage discusses interventions on the climate change issue, including voiced criticism of the 'failures' } \\
\text { of political figures by UK political and business elites and interests groups and others criticisms of UK elites } \\
\text { response to the issue. }\end{array}$ \\
\hline
\end{tabular}

\section{REFERENCES}

[1] Altheide, D. \& Snow, R. P. (1991). Media Worlds in the Postjournalism Era. Hawthorne, NY: Aldine de Gruyter Anderson, A. (1999). Media Culture and the Environment. London: Routledge

[2] Anderson, A. (2003).'Environmental activism and news media', in S.Cottle (ed.) News Public Relations and Power. London: Sage

[3] Anderson, A. (2009). 'Media, politics and climate change: Towards a new research agenda'. Sociology Compass 3(2):166-182

[4] Antilla, L. (2005) 'Climate of scepticism: US newspaper coverage of the science of climate change',Global Environmental Change, 15: 338-352

[5] Baker, P. and McEnery, A. (2005). 'A corpos-based approach to discourses of refugees and asylum seekers in UN and newspaper texts' Language and Politics: 4(2) 197-226

[6] Beck, U. (1992). Risk Society. London: Sage

[7] Bennett, W. L. (1990). 'Toward a theory of press-state relations in the United States'. Journal of Communication, 40 (2), pp $103-125$

[8] Boykoff, M and Rajan, R. (2007) 'Signals and noise: Mass-media coverage of climate change in the USA and UK', EMBO Reports, 8(3) 207-211

[9] Boykoff, M and Roberts, T (2007). 'Media coverage of climate change: Current trends, strengths and weaknesses', Human Development Report Occasional Paper 2007/08. UN Development Programme. http://hdr.undp.org/en/reports/glo bal/hdr2007-2008/papers/boykoff, \%20maxwell\%20and\%20 roberts, \%20j.\%20timmons.pdf (accessed January, 2012).

[10] Castells, M. (1997). The Power of Identity. Oxford: Blackwell

[11] Carvalho, A. and Burgess, J. (2005). 'Cultural circuits of climate change in the UK broadsheet newspapers', Risk Analysis, 25(6): 1457-1469

[12] Cottle, S. (2009). 'Ecology and climate change: From science and sceptics to spectacle and ...', in S.Cottle (ed). Global Crisis Reporting: Journalism in the Global Age. Maidenhead: OU Press

[13] Doyle, J. (2007). 'Picturing the climat(c)ic: Greenpeace and the representational politics of climate change', Science as Culture, 16(2):129-150

[14] Eder, K. (1996). The Social Construction of Nature: A Sociology of Ecological Enlightenment. London: Sage

[15] Entman, R. M. (2004). Projections of Power: Framing News, Public Opinion and U.S. Foreign Policy. London: University of Chicago Press

[16] Gaber, I. (2000) 'The Greening of the public, politics and the press, 1985-1999' in J. Smith (ed). The Daily Globe: Environmental Change, the Public and the Media. London: Earthscan

[17] Gurevitch M., M. Levy and Roeh, I. (1991). 'The global newsroom: Convergences and diversities in the globalisation of television news', in P. Dahlgren and C. Sparks (eds) Communications and Citizenship: Journalism and the Public Sphere in the New Media Age. London: Routledge

[18] Habermas, J. (1971). Toward A Rational Society. London: Heinemann

[19] Habermas, J (1998/ 1976). Legitimation Crisis. Cambridge: Polity Press

[20] Hallin, D. (1986). The 'Uncensored War': The Media and Vietnam. Oxford: Oxford University Press 
[21] Hannigan, , J. (2006). Environmental Sociology - 2nd Edition/ London: Routledge

[22] Held, D. (2006). Models of Democracy - 3rd Edition. Cambridge: Polity.

[23] Holmes, T. (2010). 'PR, "impartiality" and power in mass media coverage of climate change', in T.Boyce and J.Lewis (eds). Climate Change and the Media. Oxford: Peter Lang

[24] Levy, David L. and Andre Spicer (2013). Contested Imaginaries and the Cultural Political Economy of Climate Change. Organization, 20(5): 659-678

[25] Lockwood, A.( 2010). 'Preparations for a post-Kyoto media coverage of UK climate policy' in T.Boyce and J. Lewis (eds). Climate Change and the Media. Oxford: Peter Lang

[26] Matthews, J. and Brown A,R (2012). Negatively shaping the asylum agenda? The representational strategy and impact of a tabloid news campaign. Journalism Criticism, Theory and Practice 13(6): 802-817

[27] Matthews, J. (2015). Maintaining a politicized climate of opinion? Examining how political framing and journalistic logic combine to shape speaking opportunities in UK elite newspaper reporting of climate change. Public Understanding of Science (September 7, 2015 doi: 10.1177/0963662515599909).

[28] Monbiot, G. (2007). Heat: How to Stop the Planet from Burning. Cambridge, MA: South End Press
[29] Nohrstedt, S.A. (2010). 'Threat society and the media', in S.A. Nohrstedt (ed.) Communicating Risks: Towards the Threat Society? Gothenbeg: Nordicom

[30] Shehata, A \& Hopmann, D. (2012) Framing Climate Change, Journalism Studies, 13:2, 175-192

[31] Tosse, S. (2013). 'Aiming for social or political robustness? Media strategies among climate scientists', Science Communication, 35(1): 32-55

[32] Trumbo, C. (1996). 'Constructing climate change: Claims and frames in US news coverage of an environmental issue', Public Understanding of Science, 5:269-283

[33] Weingart, P. Engels, A and Pansegrau, P. (2000). 'Risks of communication: Discourses on climate change in science, politics and the mass media', Public Understanding of Science, 9: 261-283

[34] Wilkins, L and Patterson, P. (1991). 'Science as symbol: The media chills the Greenhouse Effect', in L.Wilkins and P. Patterson (eds) Risky Business: Communicating Issues of Science, Risk and Public Policy. London: Greenwood Press

[35] Zehar, S. (2010). 'An environmentalist / economic hybrid frame in US press coverage of climate change, 2000-2008', in T.Boyce and J.Lewis (eds). Climate Change and the Media. Oxford: Peter Lang

\footnotetext{
${ }^{\mathrm{i}}$ There is a distinction to recognise between the framing of issues and the framing of story themes. This research is concerned with recording the wider political framing of climate change as these are reproduced in news coverage. It does not treat the presence of story themes as framing (the distinction between these types has been the subject of recent debates in the framing literature). However, the research does take seriously the journalistic mediation of story themes and include them in its wider view of the determinants of news access opportunities.

ii The numbers of stories by newspaper are as follows: The Times 352 (25.5); The Telegraph 210 (15.2); The Independent 297 (21.2) and The Guardian 520 (37.7)
} 